\title{
28 \\ A CASE STUDY OF URBAN TREES, PUBLIC HEALTH AND SOCIAL EQUITY
}

\author{
MICHAEL BENTLEY
}

\begin{abstract}
Research demonstrates positive associations between urban greenness and human health; yet, the underlying causal mechanisms are less well understood. Moreover, urban greenness is distributed inequitably. This chapter describes a case study that explores some of the ways in which the quality and quantity of urban trees (as an aspect of urban greenness) relate to public health and social equity in a southern Australian context. The research used a theoretically informed, ecological public health model derived from four foundational principles of ecological public health - conviviality, equity, sustainability and global responsibility - to reveal a set of ecohealth-promoting mechanisms linking urban greenness to public health and social equity. Ecohealth in urban areas is created and lived by its human and non-human inhabitants within the convivial settings of their everyday life. While social determinants shape the health of people, the socio-natural processes of urban environmental metabolism shape urban development and the quality and distribution of trees as an urban forest. As urban trees can affect health and well-being positively, their uneven distribution is inequitable. Further case studies are needed to understand how urban trees relate to environmental and social determinants of health in different urban contexts.
\end{abstract}

\section{Introduction}

A marvellous thing about trees is that they solve their problems without moving. They are model citizens, decorative, quiet, calm and courageous. (Joignot, 2012, p. 28) 
The dynamic process of global urbanisation, what Rayner and Lang (2012) call the 'urban transition', is resulting in the rapid growth of urban areas with more than one million people (Sadler et al., 2010). In these urban areas, the external environment comprises two distinct, juxtaposed spaces: 'grey space' and 'green space', which can be broken down further, as Figure 28.1 depicts.

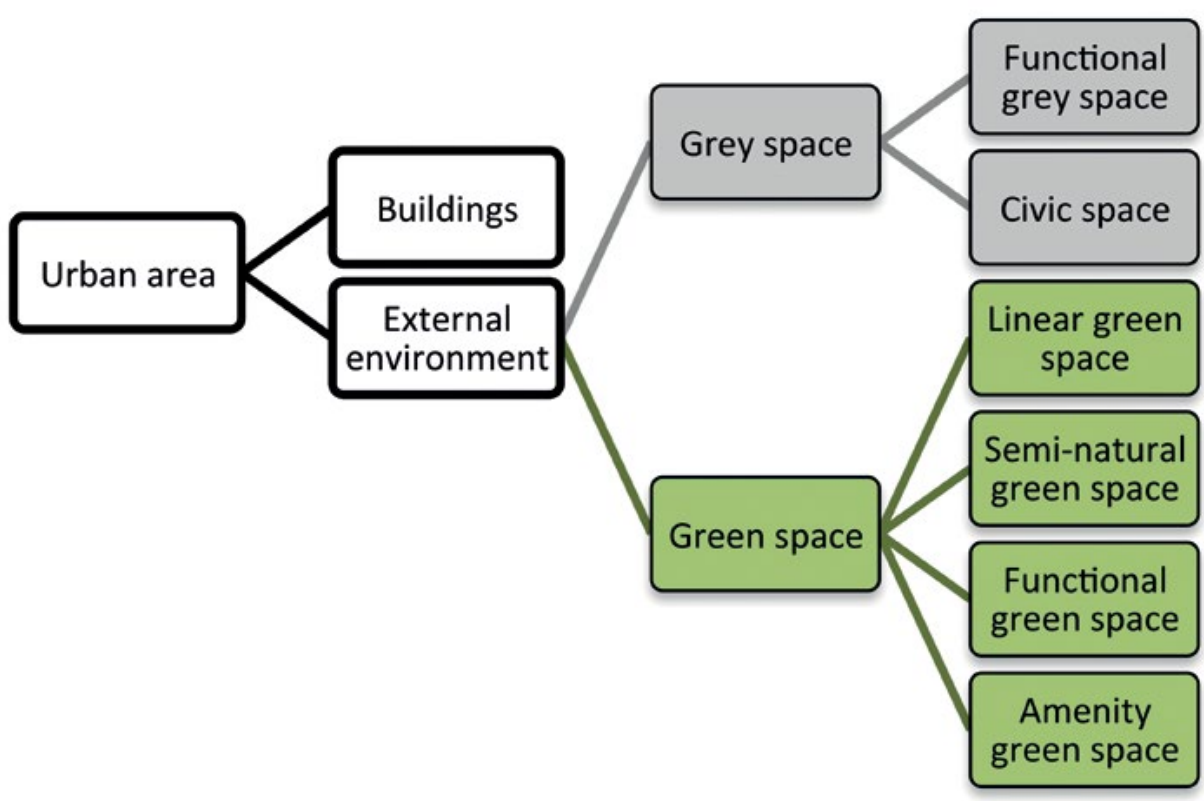

\section{Figure 28.1 Grey and green space in urban areas.}

Source: Adapted from Swanwick et al., 2003.

The increasingly dense urban built environment is placing pressure on the infrastructure of green spaces - the trees, parks and gardens. The health and well-being benefits of green space have been documented widely (Bell et al., 2008; Maas et al., 2009; Sadler et al., 2010). The green infrastructure is related to a healthy social ecosystem (Kuo, 2003), which is also important for urban biodiversity (Hostetler et al., 2011).

Trees are a significant element of green space and feature in all four classes (Figure 28.1). Urban trees are considered important for many reasons. Environmentally, there are benefits from having trees in urban areas. Urban trees contribute towards mitigating the heat island effect in cities (Coutts et al., 2013) and sequestering carbon (Nowak and Crane, 2002). Urban trees have substantial social (Kuo, 2003) and economic (Moore, 2009) value. Nevertheless, trees are distributed inequitably in cities (Landry and Chakraborty, 2009). The spatial distribution of urban trees in Australia has been shown to be related to 
income and education - areas of socio-economic disadvantage have fewer trees (Kirkpatrick et al., 2011), which raises concerns for social and environmental justice (Heynen and Perkins, 2005), and for public and community health (Nilsson and Sangster, 2008; Coutts et al., 2013).

Tony McMichael stressed the importance of the 'complex social and environmental systems that are the context for human health, [and] thinking more about population health in ecologic terms' (McMichael, 1999, p. 896). By way of this chapter, I add a mere leaf to McMichael's tree of knowledge by exploring some of the ways in which urban trees relate to public health and social equity. In so doing, I use a case study based on research conducted in suburban areas in Adelaide, South Australia (Bentley, 2012).

\section{Research Methodology}

The research (on which the case study draws) was situated in a critical realist paradigm and used critical methodological pluralism, a methodology which combines theory and methods to come up with an explanation of the phenomenon of interest (Danermark et al., 2002). The research question was: In what ways does urban greenness relate to public health and social equity in a southern Australian context? The case study explores the patterns produced by the underlying mechanisms linking urban trees to public health and social equity, and the context in which these patterns occur. Knowledge about the underlying mechanisms can be 'actively constructed from facts, events and experience' (Poland et al., 2008, p. 307), using various theoretical perspectives to understand and explain underlying structures. In other words, to understand the context and reveal the underlying mechanisms needs more than empirical data alone. The choice of methods in a critical realist enquiry is generally mixed methods and case studies. From a critical realist perspective, it is important that mixing methods 'must be governed not only by the research question but, more fundamentally, also by the ontological perspective from which you proceed' (Danermark et al., 2002, p. 153). That is, critical methodological pluralism is critical ... in the sense that it opposes an unreflecting employment of methods' (Danermark et al., 2002, p. 176).

The methods in this research were a mix of intensive and extensive procedures. Critical realist research reframes qualitative and quantitative methods as intensive and extensive procedures to identify the 'generative mechanisms [of urban trees] and describe how they are manifested in real events and processes' (Danermark et al., 2002, p. 162). Intensive methods 'focus on generative mechanisms' and extensive methods look at the 'empirical patterns produced by a particular mechanism or structure of mechanisms' (Danermark et al., 2002, pp. 165-6). 
I employed a variety of extensive methods (mapping, analysis of census and social health data, narrative reviews and summaries of relevant plans and policies, local newspaper media) and intensive methods (analysis of researchers' field notes and secondary analysis of interviews $(n=38)$ from the 'Location and Health' project (Baum et al., 2007), observational methods - field notes, photography and sound recordings) in the study.

The research found that while social determinants of health and health equity, such as income, education and housing, still shape the health of people, urban metabolism is the main driving mechanism behind the inequitable distribution of trees (as the canopy of the urban forest), and how the urban forest relates to public health and social equity.

\section{The Adelaide Case Study}

The case study looks at four suburbs of Adelaide, the capital city of South Australia. Adelaide's linear position between the Adelaide Hills and Gulf St Vincent defines and constrains its geography. Two of the suburbs are located in the northern metropolitan area - an area of relative most socio-economic disadvantage. The northern metropolitan area developed from pre-existing open woodland areas and experienced an urban sprawl, largely because of the post-war population boom that sought employment in the then new manufacturing industries. The decline in manufacturing has resulted in high levels of unemployment and social housing. The other two suburbs are in the eastern metropolitan area - an area of relative least socio-economic disadvantage. The eastern metropolitan area evolved from forested land and retained some remnant vegetation. The area contains some of the earliest colonial properties and most expensive housing. The northern case study suburbs are characterised by relatively high levels of rented housing and low levels of tertiary education (compared to the eastern case study suburbs). The eastern suburbs are relatively greener and have more than twice the household income of the northern suburbs (Table 28.1). 
Table 28.1 Suburb characteristics.

\begin{tabular}{|c|c|c|c|c|}
\hline & \multicolumn{2}{|c|}{ North } & \multicolumn{2}{|c|}{ East } \\
\hline & 1 & 2 & 1 & 2 \\
\hline \multicolumn{5}{|l|}{ Housing tenure type (per cent) } \\
\hline Fully owned & 18 & 25 & 46 & 53 \\
\hline Rented & 49 & 42 & 19 & 11 \\
\hline SEIFA IRSD ${ }^{a}$ score & 745 & 788 & 1,097 & 1,123 \\
\hline SEIFA IRSD quintile ${ }^{b}$ & 5 & 5 & 1 & 1 \\
\hline Median household income (A\$) & 561 & 578 & 1,182 & 1,597 \\
\hline Median household size (persons) & 2.4 & 2.4 & 2.4 & 2.7 \\
\hline $\begin{array}{l}\text { Proportion of people with tertiary } \\
\text { (bachelor degree or higher) education (per cent) }\end{array}$ & 5 & 9 & 52 & 52 \\
\hline $\begin{array}{l}\text { Proportion of houses with street/front yard tree } \\
\text { cover (per cent) }\end{array}$ & 24 & 50 & 78 & 88 \\
\hline Residential greenness rating (per cent) & 53 & 63 & 76 & 81 \\
\hline
\end{tabular}

Notes:

a SEIFA = socio-economic indexes for areas; IRSD = index of relative socio-economic disadvantage.

b 1 = area of relative least disadvantage; 5 = area of relative most disadvantage.

Source: Table summarised from data used in the case study of urban greenness, public health and social equity (Bentley, 2012).

Compared with the least relatively disadvantaged areas, the most relatively disadvantaged areas have worse self-rated health and higher rates of mental health problems, health risk factors (smoking, physical inactivity and obesity), chronic health conditions and premature mortality from avoidable, treatable and preventable causes (Public Health Information Development Unit, 2010, p. 96).

Adelaide's geographical position also makes it a unique urban biological entity (Tait, 2005). The presence of trees is a significant contributor to objective and subjective measures of greenness (Tait et al., 2005). Urban greenness is distributed inequitably in Adelaide. The distribution of vegetation is uneven across metropolitan Adelaide, with the south-eastern suburbs rating highly compared with the remaining suburbs in the north, west and south. Importantly, the 'lack of greenness could not be totally attributed to the current level of land use factors' (Goodwins and Noyce, 1993, p. 3). This pattern persists to the current day (see the contrasting levels of tree cover in Figure 28.2). 


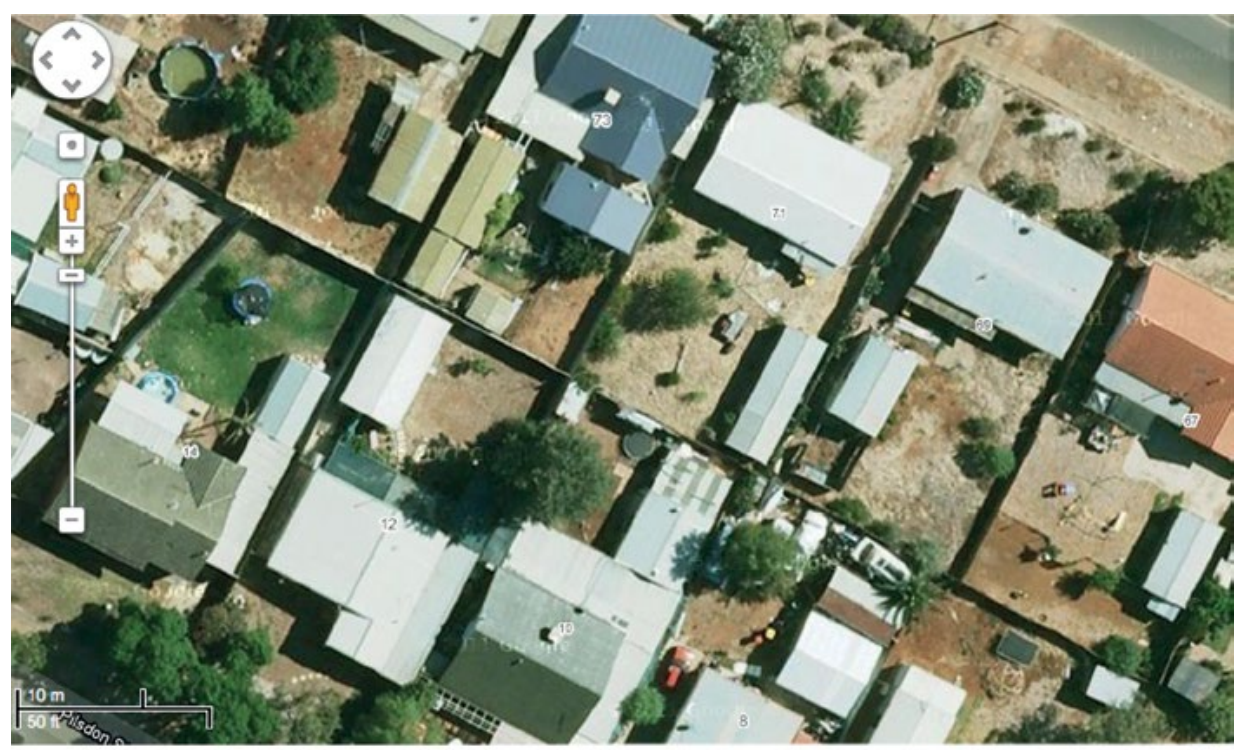

NORTH 1 Proportion of houses with street/front tree cover: $24 \%$ Median tree cover score: $2.0(n=7)^{\mathrm{a}}$

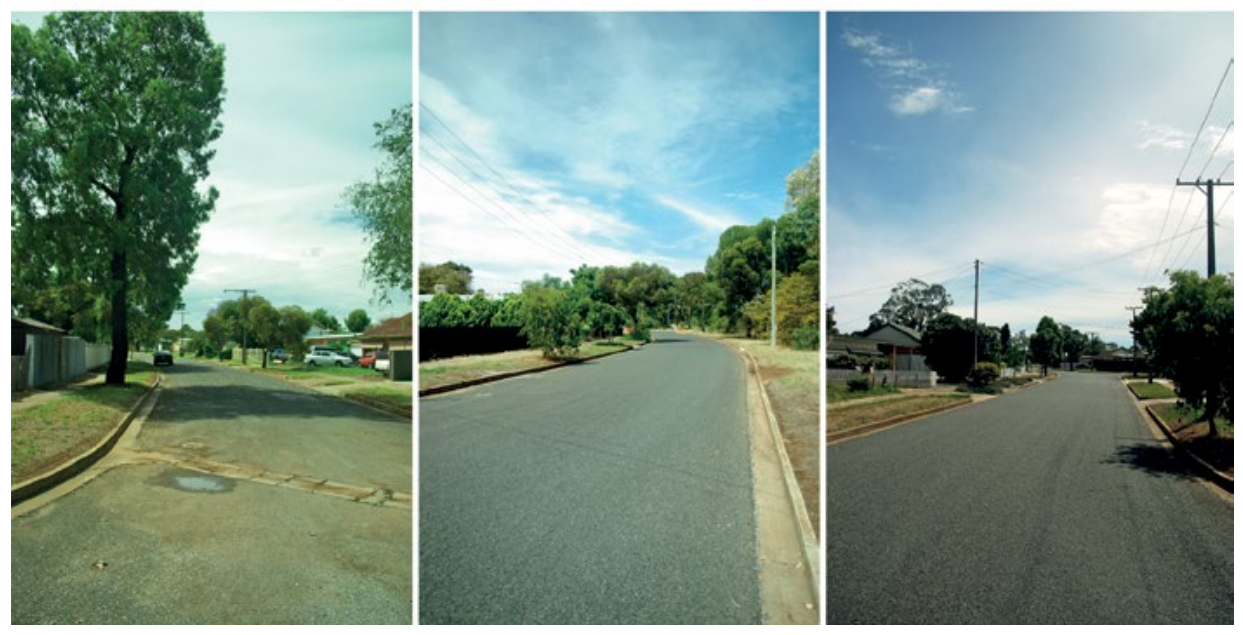

\section{Figure 28.2 Characteristics of urban trees in northern and eastern Adelaide suburbs.}

Source: Google, DigitalGlobe (overhead images above are at the same $10 \mathrm{~m}$ scale) and author's photographs. ${ }^{b}$

\section{Notes:}

a Tree cover score is derived from $3 \times 3$ grids overlayed on street-level photographs and measuring the number of squares with tree cover. For instance, in the left hand North 1 photo above, tree cover makes up 3.0 squares out of the nine squares. All photographs were taken on consecutive days in early summer at street intersections (automatic exposure with ISO 100 and $18 \mathrm{~mm}$ lens settings).

${ }^{\mathrm{b}}$ Note that, for conciseness, one northern and one eastern suburb are featured in this figure. 


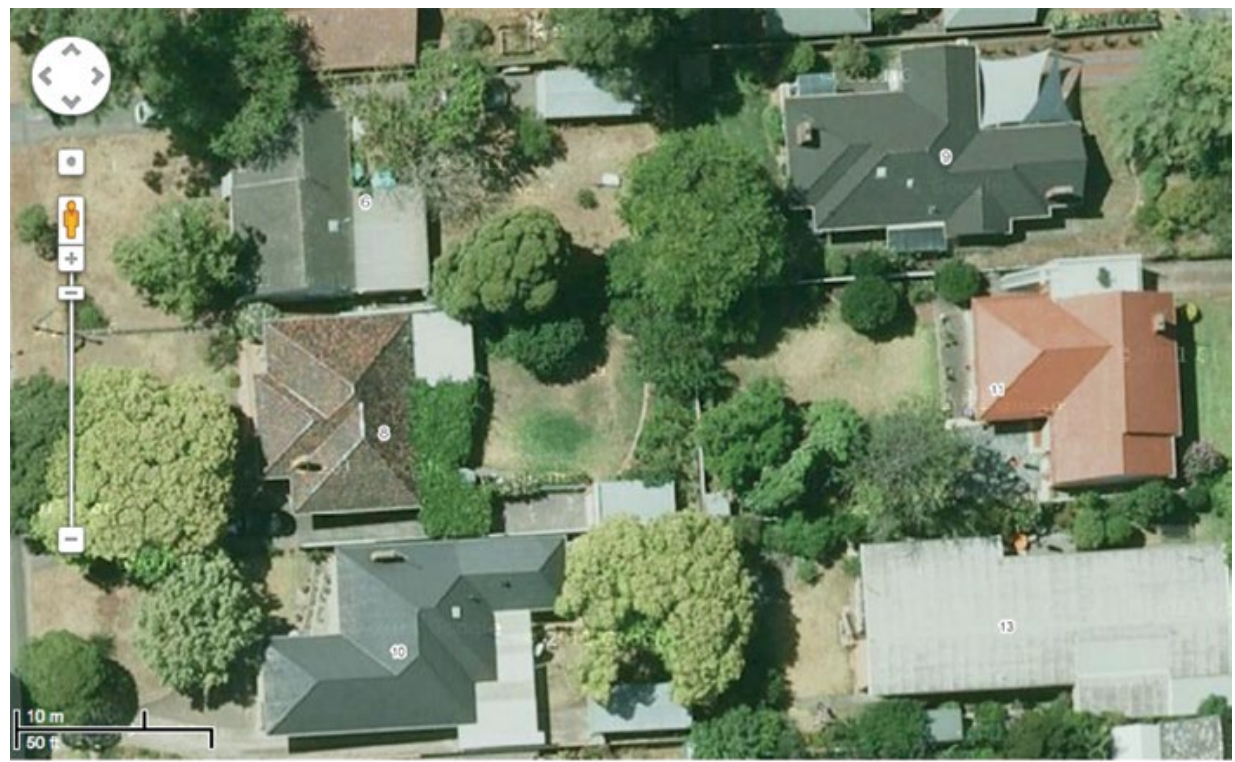

EAST 2 Proportion of houses with street/front tree cover: $88 \%$ Median tree cover score: $3.8(n=10)$
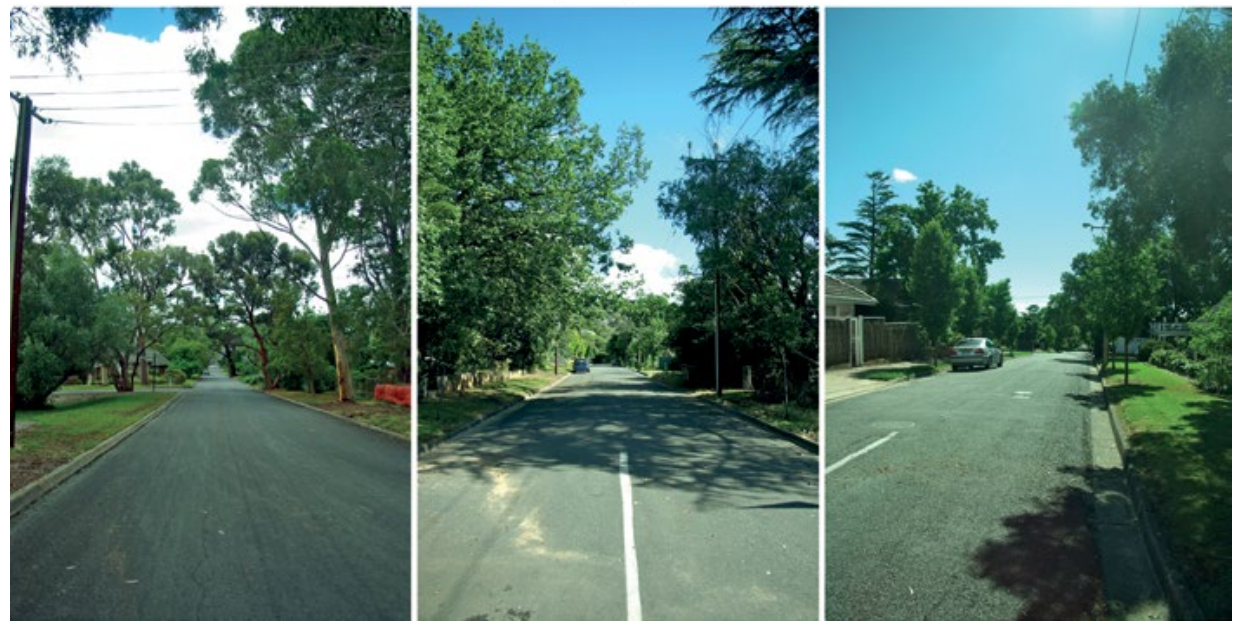

This case study will not be generalisable to rural areas or to urban areas in poorer countries. However, in relation to generalisability, case studies 'are generalizable to theoretical propositions and not to populations or universes' (Yin, 2009, p. 15). A benefit of using a critical realist approach is that explanation, which is based on theory and methods, can provide theoretical generalisability (Yin, 2009) to similar contexts. 


\section{Theoretical Perspective}

Place-sensitive approaches will enable scholars of well-being to better appreciate the significance of local interconnections that frame the lives of local populations and their experience of (and relationships with) environments and socio-cultural values attached to these locations. (Panelli and Tipa, 2007, p. 456)

This case study is place based. However, places (neighbourhoods, local areas, etc) are also part of an open ecosystem. Thus, the case study takes an ecological public health perspective, which acknowledges humans as part of the ecosystem, not separate from it (Rayner and Lang, 2012). There are broader public health concerns that affect the health of humans and the ecosystem (e.g. water, pollution, climate change). There are social aspects that affect well-being (e.g. amenity, access to green space) differentially. Moreover, social equity is related to environmental equity in urban areas (Falk et al., 1993), which also has consequences for the well-being of the non-human inhabitants (e.g. loss of habitat, reduced biodiversity).

The ecological public health thinking behind the case study is based on a theoretically derived model of ecological public health, which describes the relationships between different convivial communities interacting with each other in equitable ways (Bentley, 2014). Theories of more-than-human agency (the activities of non-human actors) inform ways of living together (conviviality) in urban areas. Political ecology links the equity concerns about environmental and social justice. At the core of this ecological public health thinking is the concept of conviviality. According to the Oxford dictionary, the origin of 'conviviality' lies in the Latin convivialis, which can be taken literally to mean 'live with'. In an ecological sense, this can connote the relations of the entities of an environment to each other and their surroundings. Conviviality necessitates a shift in thinking separately about health and ecology. Living with the nonhuman inhabitants of urban areas opens up new ways of thinking about health ecology and the equitable distribution of convivial areas. Conviviality has been conceptualised as 'a political project that is concerned with a more broadly conceived accommodation of difference, better attuned to the comings and goings of the multiplicity of more-than-human inhabitants that make themselves at home in the city' (Hinchliffe and Whatmore, 2006, p. 125).

In an ecological sense, nature is part of the urban fabric. In Australia, a general pattern is for people to separate the natural environment from their built environment (Head and Muir, 2005). The private space of the backyard (or back garden) is best for people and the natural environment (the 'bush' in Australia) is best for wildlife. Nevertheless, in between these spaces, people and wildlife 
encounter each other in the green infrastructure of neighbourhoods, streets, local parks and bushland areas in different ways. Urban trees play an active role, for example, in providing shade, ameliorating the local climate and acting as a wildlife corridor. This is not to say that trees 'possess the particular and extraordinary capabilities of humans ... [but] they do possess very significant forms of active agency, which have usually been assumed to exist only in the human realm' (Jones and Cloke, 2008, p. 81). It is the role and distribution of trees that I now focus on.

\section{The Urban Metabolism of Trees}

Trees are part of the connections and interactions between people and things. Local government councils plant street trees and maintain public parks and gardens. Homeowners (and many home renters) create, alter and maintain private gardens (some spilling out on to the public footpaths).

The concept of urban metabolism has been used in socioecological frameworks for health to illustrate how physical and social resources are transformed or metabolised by urban systems and processes, resulting in outcomes that influence liveability, environmental quality and waste (Kearns et al., 2007; Schandl et al., 2012).

In this chapter, I propose that urban trees and urban forests are central to the processes of urban metabolism: they contribute to mitigating air pollution, harvesting stormwater, ameliorating heat island effects and providing psychosocial or mental support to humans who interact with them. They contribute to an aesthetic quality that is related to a healthy social ecosystem (Kuo, 2003). Key to their ongoing existence and care are political processes that may or may not protect them; for example, pressures on urban development, road clearances, dangers from falling limbs to pedestrians and drivers, risk of same-species disease transmission. Political contestations around urban forests lead to their uneven distribution, with the socio-natural transformations of urban forests changing urban areas in ways that may be health promoting or damaging. From an equity perspective, these political processes produce unjust outcomes.

Urban forests are socially produced (Heynen and Perkins, 2005). For example, with the exception of some significant trees in the eastern metropolitan area that pre-date European settlement, most of Adelaide's urban forest has evolved since 1,836. All 38 native tree species remain, and 60 introduced species have been added to the mix (Tait, 2005). Yet, the distribution remains uneven and, as urban trees affect health and well-being positively (Nilsson and Sangster, 2008), it is also inequitable. 
The socio-natural processes of urban environmental metabolism have been shown to be a strong mechanism in explaining the uneven distribution of the urban forest:

Urban trees necessarily exist within the urban built environment, and thus should be expected to change (to be cut or die and not be replanted, to be planted, etc) in relation to urban consumption patterns. These consumption patterns are necessarily related to class and other power relations. (Heynen, 2006, p. 513)

The spatial distribution of urban trees in Australia is related to income and education - areas of socio-economic disadvantage have fewer trees (Kirkpatrick et al., 2011). Housing tenure may explain some of this inequitable distribution. People who are renting dwellings are less likely to have trees in their front gardens (Kirkpatrick et al., 2011). There was a strong relationship between median household income and trees in front yards or street frontage in the case study suburbs (the correlation coefficient of median household income and trees in front yards or street frontage is 0.92 , with a coefficient of determination of 0.84). There was also a strong relationship between the proportion of dwellings being rented and trees in front yards or street frontage in the case study suburbs (the correlation coefficient of rented dwellings and trees in front yards or street frontage is -0.98 , with a coefficient of determination of 0.95 ).

Kirkpatrick et al. also found an association between rates of unemployment and the density of street/front garden trees and concluded:

It would be possible to plan to double the number of street trees in Australian cities in present circumstances, but that significant increases in garden tree numbers would depend on increasing the income and higher education attainment of lower socio-economic groups. (Kirkpatrick et al., 2011, p. 244)

The social equity statistics in the Adelaide case study support this conclusion. The different proportions of higher education attainment in the northern (less than 10 per cent) and eastern (over 50 per cent) suburbs are stark. The median household income in eastern suburbs is more than twice that of the northern suburbs (Table 28.1).

Heynen (2006) draws on the concept of the consumption fund of the urban built environment - 'the circuit of capital that contains most urban ecological resources, such as urban forests, that are vital to the health of urban systems in general' (Heynen and Perkins, 2005, p. 105) - to show how political processes 
contribute to urban forest metabolism. ${ }^{1}$ In Heynen's study, 'median household income was shown to significantly contribute to local metabolization in urban forest canopy cover and residential forest canopy cover' (Heynen, 2006, p. 513). There was a similar finding in the Adelaide case study. Furthermore, in the Adelaide case study, activism to save urban trees was strongest in more affluent areas, which supported the hypothesis that community groups could contribute to an uneven canopy cover (Conway et al., 2011).

In the Adelaide case study, the agency of trees was acknowledged in interviews with residents from the areas of relatively higher income and relatively less disadvantage, where the urban forest was denser:

We have the beautiful gentle breezes at night on a hot day. It's generally cooler where we are because of the shade of the trees, so it's very pleasant from that perspective visually as well. (Female, 49 years old, East 1)

The agency of trees has some explanatory power in informing ways of living together (conviviality) in urban areas and casting biodiversity in a new light. Large urban trees play an important role in providing vital habitat resources for the city's non-human inhabitants (Stagoll et al., 2012). But, the respondent above also saw a downside of trees and yet, at the same time, acknowledged the need to live together with them.

[The trees have] always been an issue because they block our drains and they're staining our pavers ... But the nice thing is and the important thing is I love the trees, I just wish they weren't gum trees. ... getting a house somewhere where there's no trees would be awful because you wouldn't get the lovely birds in the morning, so it's a compromise, so we've had to learn to live with them. (Female, 49 years old, East 1)

These comments reflect the dichotomous positions on trees in suburban areas. For instance, people like the bird life that trees attract, but not the risk of falling limbs (Head and Muir, 2005). Local media reports from the eastern suburbs highlight these risk concerns.

Sheltering under trees may not be such a hot idea: Looking for shade under a tree may not be the greatest idea, with the SES reporting a growing number of falling branches during the current heatwave. SES deputy chief officer Matt Maywald says trees can drop their branches without warning during hot weather. 'Commonly eucalypts are affected, but the problem is not limited to this variety of tree, so people should not be complacent,' Mr Maywald said. ... The SES is advising people to

1 Heynen uses 'metabolism' rather the more neutral 'change', as the socio-natural transformations of urban areas are the result of neoliberal political processes. 
avoid standing or parking under trees with large, overhanging branches and to ensure their children do not climb or play around at-risk trees. (Eastern Courier, 13 November 2009)

Tree policy goes out on a limb: Falling tree limbs that cause property damage, injury and even death are looming as a 'significant risk' for councils, prompting an independent inquiry into tree management by the Local Government Association (LGA). The LGA says the recent drought, combined with the overall ageing of Adelaide's street trees, has led to a significant increase in falling branches recently. (Eastern Courier, 27 April 2010)

Trees also featured prominently in local news stories from the eastern suburbs, in the context of the prolonged drought that affected much of south-eastern Australia from 2003 to 2010.

Summer's new autumn for Adelaide streetscapes: Still in summer, yet some parts of the city already look like mid-autumn. Adelaide's deciduous trees, such as plane trees, are dropping leaves weeks earlier than usual, apparently caused by the scorching summer and ongoing drought. University of Adelaide tree expert Dr Jennifer Watling said the trees were suffering from heat and water stress. (Eastern Courier, 25 February 2009)

1800 eastern trees axed: More than 1800 dead, dying or dangerous trees have been axed across the drought-ravaged eastern suburbs this past year, sparking calls for more stormwater harvesting. ... Treenet Director David Lawry - whose organization researches the state of local trees and gives feedback to councils and communities - said people had 'no right to blame' climate change for killing trees in the east, considering Adelaide was losing 160 gigalitres of stormwater each year instead of harvesting it. (Eastern Courier, 8 September 2009)

What was also notable in the case study was the uneven distribution of watered private gardens across the case study suburbs. Most of the northern blocks are reasonably sized. Many yards are not watered. There are few trees in the backyards. Most of the eastern blocks are also reasonably sized. Yet, most yards have some watered areas. All the yards have one or more trees (Figure 28.2). This pattern follows the income distribution. That is, the high-income suburbs have more watered areas. The price of water in Adelaide has a fixed (watersupply charge) and a variable (water-use charge) component.

On the whole, there is an unequal distribution of the urban forest across the case study suburbs that is related to household income and housing tenure, two of the social determinants of health. Moreover, the processes of urban metabolism 
influence the quality and quantity of urban trees and their relationship to social equity and mental health. There is a body of experimental evidence to support the restorative effects of urban greenness on mental health and well-being (Tzoulas et al., 2007). The 'Location and Health' project (Baum et al., 2007) found statistically significant differences in mental health (derived from the SF-12 standardised self-reported health measure) between the northern suburbs and the eastern suburbs. The results were lowest in the north and highest in the east. In the eastern areas of relative least socio-economic disadvantage, the case study reveals some support for the project of conviviality. There is a stronger focus on environment and biodiversity in local government plans that cover the eastern suburbs. Local government plans that cover the northern suburbs focus more on social and economic development.

\section{Discussion and Conclusion}

The Ottawa Charter for Health Promotion acknowledges that the inextricable links between people and their environment constitutes the basis for a socioecological approach to health' (World Health Organization, 1986, p. ii). There is congruence in the stand points of health promotion and urban ecology. The Ottawa Charter states: 'Health is created and lived by people within the settings of their everyday life; where they learn, work, play and love' (World Health Organization, 1986, p. iii). Relatedly, the new field of reconciliation ecology calls for 'inventing, establishing and maintaining new habitats to conserve species diversity in places where people live, work and play' (Rosenzweig, 2003, p. 7).

Further work is needed on the contribution of urban trees to public health and social equity. The geographical context is important - efforts at reconciliation ecology are strongest where access to natural corridors is closer (Loss et al., 2009). There are still gaps in knowledge about the biodiversity values of green space and ecological connectivity in urban green space (Bell et al., 2008). Moreover, as urban areas are part of an ecosystem, concerns that manifest locally may have their roots or causes in other parts of the system, climate change for instance (Wilbanks and Kates, 1999). The sustainability of the urban forest requires an understanding of the local and global thresholds that can trigger irrevocable changes in urban living. Climate change and water are two concerns likely to affect the quality of Adelaide's urban trees.

In my research, I set out to investigate the question: In what ways does urban greenness relate to public health and social equity in a southern Australian context? Through an ecological public health lens, I revealed a set of ecohealthgenerating mechanisms that manifest in the South Australian context under contingent conditions. That is to say, the answer to the research question is 
tentative - each of these mechanisms could be explored in different contexts. Others have called for 'a truly integrative framework for analysing all aspects of urban systems covering environment and health' (Schandl et al., 2012, p. 381).

This case study is a modest response to that call. The cities where the majority of the world's population now live provide a setting for human and more-thanhuman health. To understand the links between environment and health in urban areas, there needs to be a shift to biosensitive cities - 'in tune with, sensitive to, and respectful of, the processes of life' (Schandl et al., 2012, p. 382). Furthermore, an ecological public health perspective on biosensitive cities would '[refuse] the old settlements between society and nature, between humans and the rest ... [and] is serious about the heterogeneous company and messy business of living together' (Hinchliffe and Whatmore, 2006, p. 134) (italics in original). An ecological public health should be convivial, equitable, sustainable and ethical (Bentley, 2014). However, the inequitable distribution of trees as part of urban green space raises social and environmental justice concerns. It remains to assess the extent to which conviviality can inform social and environmental justice, how political ecology informs sustainable urban environments and how the local informs the global (Bentley, 2014). Further case studies are needed to understand how urban trees relate to environmental and social determinants of health in different urban contexts.

\section{References}

Baum, F., Ziersch, A., Zhang, G., Putland, C., Palmer, C., MacDougall, C., et al. 2007. People and Places: Urban Location, Social Capital and Health. Flinders University, Adelaide, Australia.

Bell, S., Hamilton, V., Montarzino, A., Rothnie, H., Travlou, P. \& Alves, S. 2008. Greenspace and Quality of Life: A Critical Literature Review. Greenspace Scotland, Stirling, Scotland, UK.

Bentley, M. 2012. Urban Greenness, Public Health and Social Equity: A South Australian Study. DrPH dissertation, Flinders University, Adelaide, SA, Australia.

Bentley, M. 2014. An ecological public health approach to understanding the relationships between sustainable urban environments, public health and social equity. Health Promotion International 29, 528-37.

Conway, T.M., Shakeel, T. \& Atallah, J. 2011. Community groups and urban forestry activity: drivers of uneven canopy cover? Landscape and Urban Planning 101, 321-9. 
Coutts, A.M., Tapper, N.J., Beringer, J., Loughnan, M. \& Demuzere, M. 2013. Watering our cities: the capacity for water sensitive urban design to support urban cooling and improve human thermal comfort in the Australian context. Progress in Physical Geography 37, 2-28.

Danermark, B., Ekström, M., Jacobsen, L. \& Karlsson, J.C. 2002. Explaining Society: Critical Realism in the Social Sciences. Routledge, London UK and New York, USA.

Falk, J., Hampton, G., Hodgkinson, A., Parker, K. \& Rorris, A. 1993. Social Equity and the Urban Environment: Report to the Commonwealth Environment Protection Agency. University of Wollongong, Wollongong, NSW, Australia.

Goodwins, D. \& Noyce, T. 1993. A 'Greenness' Rating for the Suburbs of Metropolitan Adelaide. Government of South Australia, Adelaide, SA, Australia.

Head, L. \& Muir, P. 2005. Living with trees - perspectives from the suburbs. In: Calver, M., Bigler-Cole, H., Bolton, G., Dargavel, J., Gaynor, A., Horwitz, P., Mills, J., Horwitz, P. \& Wardell-Johnson, G. (eds) Proceedings of the 6th National Conference of the Australian Forest History Society. Millpress, Rotterdam, The Netherlands, 84-95.

Heynen, N. 2006. Green urban political ecologies: toward a better understanding of inner-city environmental change. Environment and Planning A 38, 499-516.

Heynen, N. \& Perkins, H.A. 2005. Scalar dialectics in green: urban private property and the contradictions of the neoliberalization of nature. Capitalism Nature Socialism 16, 99-113.

Hinchliffe, S. \& Whatmore, S. 2006. Living cities: towards a politics of conviviality. Science as Culture 15, 123-38.

Hostetler, M., Allen, M. \& Meurk, C. 2011. Conserving urban biodiversity? Creating green infrastructure is only the first step. Landscape and Urban Planning 100, 369-71.

Joignot, F. 2012. Trees give us more than we recognise. The Guardian Weekly $186,28-9$.

Jones, O. \& Cloke, P. 2008. Non-human agencies: trees in place and time. In: Knappett, C. \& Malafouris, L. (eds) Material Agency: Towards a Nonanthropocentric Approach. Springer, New York, USA, 79-96.

Kearns, A., Beaty, M. \& Barnett, G. 2007. A socio-ecological perspective on health in urban environments. NSW Public Health Bulletin 18, 48-50. 
Kirkpatrick, J.B., Daniels, G.D. \& Davison, A. 2011. Temporal and spatial variation in garden and street trees in six eastern Australian cities. Landscape and Urban Planning 101, 244-52.

Kuo, F. 2003. The role of arboriculture in a healthy social ecology. Journal of Arboriculture 29, 148-55.

Landry, S.M. \& Chakraborty, J. 2009. Street trees and equity: evaluating the spatial distribution of an urban amenity. Environment and Planning A 41, 2651-70.

Loss, S.R., Ruiz, M.O. \& Brawn, J.D. 2009. Relationships between avian diversity, neighborhood age, income, and environmental characteristics of an urban landscape. Biological Conservation 142, 2578-85.

Maas, J., Verheij, R.A., de Vries, S., Spreeuwenberg, P., Schellevis, P.F.G. \& Groenewegen, P.P. 2009. Morbidity is related to a green living environment. Journal of Epidemiology and Community Health 63, 967-73.

McMichael, A.J. 1999. Prisoners of the proximate. Loosening the constraints on epidemiology in an age of change. American Journal of Epidemiology 149, 887-97.

Moore, G.M. 2009. Urban trees: worth more than they cost. 10th National Street Tree Symposium. Available at: www.treenet.org/symposium/proceedingsarchive/symposium-2009/?vid=3, accessed 18 February 2015.

Nilsson, K. \& Sangster, M. 2008. Forests, trees and human health and wellbeing. Forest and Landscape. Cost Action E39, Copenhagen, Denmark.

Nowak, D. \& Crane, D. 2002. Carbon storage and sequestration by urban trees in the USA. Environmental Pollution 116, 381-9.

Panelli, R. \& Tipa, G. 2007. Placing well-being: a Maori case study of cultural and environmental specificity. EcoHealth 4, 445-60.

Poland, B., Frohlich, K.L. \& Cargo, M. 2008. Context as a fundamental dimension of health promotion program evaluation. In: Potvin, L. \& McQueen, D. (eds) Health Promotion Evaluation Practices in the Americas. Springer, New York, USA, 299-317.

Public Health Information Development Unit 2010 (cited in Bentley, 2012, p. 96). www.adelaide.edu.au/phidu/, accessed 2 July 2015.

Rayner, G. \& Lang, T. 2012. Ecological Public Health Reshaping the Conditions for Good Health. Routledge/Earthscan, Abingdon, UK. 
Rosenzweig, M. 2003. Win-win Ecology: How Earth's Species Can Survive in the Midst of Human Enterprise. Oxford University Press, New York, USA.

Sadler, J., Bates, A., Hale, J. \& James, P. 2010. Bringing cities alive: the importance of urban greenspaces for people and diversity. In: Gaston, K. (ed.) Urban Ecology. Cambridge University Press, Cambridge, UK, 230-60.

Schandl, H., Boyden, S., Capon, A. \& Hosking, K. 2012. 'Biosensitive' cities - a conceptual framework for integrative understanding of the health of people and planetary ecosystems. Current Opinion in Environmental Sustainability 8, 378-84.

Stagoll, K., Lindenmayer, D.B., Knight, E., Fischer, J. \& Manning, A.D. 2012. Large trees are keystone structures in urban parks. Conservation Letters 5, 115-22.

Swanwick, C., Dunnett, N. \& Woolley, H. 2003. Nature, role and value of green space in towns and cities: an overview. Built Environment 29, 94-106.

Tait, C. 2005. Trees and urban green areas. In: Daniels, C. \& Tait, C. (eds) Adelaide. Nature of a City: The Ecology of a Dynamic City from 1836 to 2036. Biocity: Centre for Urban Habitats, Adelaide, SA, Australia, 101.

Tait, C.J., Daniels, C.B. \& Hill, R.S. 2005. Changes in species assemblages within the Adelaide metropolitan area, 1836-2002. Ecological Applications 15, 346-59.

Tzoulas, K., Korpela, K., Venn, S., Yli-Pelkonen, V., Kaźmierczak, A., Niemela, J., et al. 2007. Promoting ecosystem and human health in urban areas using Green Infrastructure: a literature review. Landscape and Urban Planning 81, 167-78.

Wilbanks, T. \& Kates, R. 1999. Global change in local places: how scale matters. Climatic Change 43, 601-28.

World Health Organization 1986. Ottawa Charter for Health Promotion. Health Promotion 1, i-iv.

Yin, R. 2009. Case Study Research: Design and Methods. Sage, Thousand Oaks, California, USA. 
This text is taken from Health of People, Places And Planet:

Reflections based on Tony McMichael's four decades of contribution to epidemiological understanding, edited by Colin D. Butler, Jane Dixon and Anthony G. Capon, published 2015 by ANU Press, The Australian National University, Canberra, Australia. 